\title{
Discurso publicitário: em destaque as embalagens de alimentos para criança
}

Izilda Maria NARDOCCI

Milena NARDOCCI

\section{Considerações iniciais}

Em pesquisa publicada em 2018, estudamos o gênero de discurso anúncio publicitário de alimentos ultraprocessados, veiculados pela revista Boa forma, Veja e Piauí (NARDOCCI; PAGOTTO, 2018). Neste capítulo, continuamos com o estudo de anúncio publicitário, mas focamos nas embalagens dos produtos para criança. Tendo isso em vista, os objetivos traçados são: identificar no discurso publicitário das embalagens de alimentos, selecionadas como amostra, o ethos discursivo que emerge da cenografia, visando à adesão dos co-enunciadores; verificar se tal ethos discursivo é incorporado pela análise nutricional do alimento. Fundamenta nossa pesquisa o referencial teórico-metodológico da Análise do 
Discurso, especialmente os estudos de Maingueneau (2005, 2008, 2013, 2015); os estudos de Strehlau (1996) e Mestriner (2007) sobre a gestão das embalagens e a classificação dos alimentos, proposta pelo Guia alimentar para população brasileira, do Ministério da Saúde (2014).

\section{Publicidade de alimentos e as recomendações do Guia alimentar}

A publicidade direcionada ao público infantojuvenil é um tema de constantes debates que visam proteger esse público contra o excesso de apelo. Há um arcabouço jurídico que sustenta um controle e fiscalização de tal prática como o Código de defesa do consumidor, artigo $37 \$ 2^{\circ}$, que estabelece ser

abusiva, dentre outras, a publicidade discriminatória de qualquer natureza, a que incite à violência, explore o medo ou a superstição, se aproveite da deficiência de julgamento e experiência da criança, desrespeita valores ambientais, ou que seja capaz de induzir o consumidor a se comportar de forma prejudicial ou perigosa à sua saúde ou segurança.

Por seu turno, o Estatuto da criança e do adolescente, artigo 79, institui que

as revistas e publicações destinadas ao público infantojuvenil não poderão conter ilustrações, fotografias, legendas, crônicas ou anúncios de bebidas alcoólicas, tabaco, 
armas e munições, e deverão respeitar os valores éticos e sociais da pessoa e da família.

Também o Código Brasileiro de Autorregulação Publicitária (CONAR), no capítulo II, seção 11, destaca o que deve ser observado na propaganda voltada para o público infantojuvenil, ou seja, a propaganda não pode associar crianças a situações perigosas, deve respeitar a dignidade da criança e do adolescente, não deve conter apelo de consumo.

Entre os anúncios publicitários para criança, os de alimentos são alvo de muita atenção por parte dos órgãos fiscalizadores, conforme pode ser comprovado no documentário "Muito além do peso" (2012). Resultado de pesquisas com profissionais e familiares envolvidos com a alimentação infantil, o documentário mostra que a publicidade contribui para que, entre os familiares, os alimentos ultraprocessados sejam considerados saudáveis e, portanto, não se preocupam com o consumo em excesso pelas crianças, $o$ que tem desencadeado precocemente doenças como a obesidade, o diabetes entre outras.

Como sabemos, os anúncios publicitários não são veiculados apenas pela grande mídia. Existem outras formas de divulgação de um produto como é o caso das embalagens dos próprios produtos nos pontos de venda. Seabra (2012, s/p) expõe que

numa situação de escolha, a tomada de decisão acaba assumindo aspectos de percepção psicocognitiva sob estímulos visuais. Com efeito, o poder de propaganda das embalagens assume papel de destaque e torna-se um grande fator de persuasão do olhar e do desejo do consumidor. 
Observando as embalagens de alimentos nos mercados, especialmente os ultraprocessados, é possível constatar que, de fato, suas embalagens se colocam como anunciantes de seus produtos, apelando sempre para características atualmente valorizadas pelos consumidores como menos calorias, menos gordura, menos açúcar, o que vai ao encontro do que o Ministério da Saúde propõe no Guia alimentar para população brasileira (2014).

A recomendação do Ministério da Saúde (2014) é que, na base de uma alimentação saudável, devem estar os alimentos in natura ou minimamente processados, assim como preparações culinárias feitas da combinação desses alimentos (frutas, legumes, verduras, raízes, tubérculos, ovos, arroz, feijão, leite, carne) e ingredientes culinários (sal, açúcar, azeite, manteiga) e não os alimentos ultraprocessados.

Segundo o Ministério da Saúde, grande parte dos alimentos ultraprocessados possuem alta densidade energética (muitas calorias por peso de alimento), apresentam alto teor de sódio e de gordura; são pobres em vitaminas, minerais e fibras. O Ministério da Saúde (2014, p. 41) expõe que alimentos ultraprocessados são

formulações industriais feitas inteiramente ou majoritariamente de substâncias extraídas de alimentos (óleos, gorduras, açúcar, amido, proteínas), derivadas de constituintes de alimentos (gorduras hidrogenadas, amido modificado) ou sintetizadas em laboratório com base em matérias orgânicas como petróleo e carvão (corantes, aromatizantes, realçadores de sabor e vários tipos de aditivos usados para dotar os produtos de propriedades sensoriais atraentes). Técnicas de manufatura incluem extrusão, moldagem, e pré-processamento por fritura ou cozimento. 
Os alimentos ultraprocessados, em razão da sua formulação e de seus ingredientes, são nutricionalmente desbalanceados. Tendem a ser consumidos em excesso, substituindo os alimentos in natura ou minimamente processados. A fabricação de alimentos ultraprocessados é feita por indústrias de grande porte e envolve muitas etapas e técnicas de processamento com a adição de ingredientes como sal, açúcar, óleo, mas também de substâncias de uso exclusivamente industrial, como proteína de soja e de leite, extratos de carnes, gorduras e aditivos sintetizados em laboratórios.

Os aditivos alimentares comumente utilizados em alimentos ultraprocessados contribuem para ampliar a duração desses alimentos, além de dar cor, sabor, aroma e textura a eles, o que os torna extremamente atraentes. Nesses produtos, quando há alimentos in natura, a quantidade é sempre muito reduzida. Segundo o Ministério da Saúde (2014, p. 40), "as técnicas de processamento utilizadas na fabricação de alimentos ultraprocessados incluem: tecnologias exclusivamente industriais, como a extrusão da farinha de milho para fazer salgadinhos 'de pacote', versões industriais de técnicas culinárias, como o pré-processamento com fritura ou cozimento".

São classificados como alimentos ultraprocessados

bebidas adoçadas com açúcar ou adoçantes artificiais, pós para refrescos, embutidos e outros produtos derivados de carne e gordura animal, produtos congelados prontos para aquecer, produtos desidratados (como misturas para bolo, sopas em pó, "macarrão" instantâneo e "tempero" pronto), os vários tipos de salgadinhos "de pacote", cereais matinais, barras de cereal, bebidas energéticas, entre muitos outros. Pães e produtos panificados 
tornam-se alimentos ultraprocessados quando, além da farinha de trigo, leveduras, água e sal, seus ingredientes incluem substâncias como gordura vegetal hidrogenada, açúcar, amido, soro de leite, emulsificantes e outros aditivos (MINISTÉRIO DA SAÚDE, 2014, p. 40).

Para se reconhecer um alimento ultraprocessado, uma das estratégias é verificar a lista de ingredientes, pois possuem uma longa lista em que muitos são desconhecidos. Esses alimentos, geralmente, são consumidos ao longo do dia, substituindo alimentos in natura ou minimamente processados, como frutas, leite, água e, às vezes, até substituindo refeições principais. As embalagens dos alimentos ultraprocessados são sofisticadas, apresentam-se em vários tamanhos e apropriadas para estocagem do produto ou para consumo imediato sem utensílios domésticos.

Esses alimentos são, portanto, anunciados como práticos, possuem data de validade longa, requerem pouco ou nenhum tempo de preparo, podem ser consumidos em qualquer lugar, como no carro ou na frente da televisão e, muitas vezes, não precisam de refrigeração, como é o caso de salgadinhos, leites achocolatados e alguns tipos de queijo.

Como dissemos acima, existe um arcabouço jurídico que visa proteger a criança contra os excessos de apelo nos anúncios publicitários, principalmente, os veiculados na grande mídia, mas os produtos não são divulgados apenas por esse mídium, existem outros como a própria embalagem do produto. 


\section{Embalagens como mídium e ethos discursivo}

Debray (1995, p. 21), ao pesquisar a história das ideias, postula que existe "correlação entre as produções simbólicas de um grupo humano, suas formas de organização e seu modo de coleta, arquivamento e circulação dos vestígios". As produções simbólicas de uma sociedade, em determinado período, não podem ser explicadas sem se considerarem as tecnologias da memória utilizadas nesse mesmo período.

Segundo o autor, existe uma intersecção entre a vida intelectual, material e social. Em razão disso, ele propõe a constituição de uma disciplina chamada de Midiologia, cuja função é o estudo das mediações, do mídium, que é "o conjunto dinâmico dos procedimentos e corpos intermédios que se interpõem entre uma produção de signos e uma produção de acontecimentos" (DEBRAY, 1995, p. 28).

Debray explica que, ao transmitirmos uma mensagem, podemos entender mídium como: procedimento geral de simbolização: palavra, escrita, imagem analógica ou imagem digital; código social: língua em que é veiculada a mensagem; suporte material: argila, papiro, pergaminho, papel, banda magnética, tela; dispositivo de gravação conectado a uma rede de difusão: tipografia, televisão, informática. Então, mídium é o que é posto em movimento por uma revolução midiológica e provoca mudanças na história das sociedades.

Para Debray (1995), não se pode considerar mídium apenas no âmbito da distinção entre oralidade e escrita, que é a primeira abstração que se faz dos suportes e redes, isso deve ser ampliado. Por exemplo, se considerarmos apenas a escrita, há distinção entre aquela apresentada em um suporte de papel e uma tela de compu- 
tador. Entre elas, há mudanças técnicas, culturais e sociais que não nos permitem concebê-las como um mesmo mídium.

Com base nos estudos de Debray, Maingueneau (2005, p. 71) expõe:

É necessário reservar um lugar importante ao modo de manifestação material dos discursos, ao seu suporte, bem como ao seu modo de difusão: enunciados orais, no papel, radiofônicos, na tela do computador.

O autor explica que mídium não é apenas a forma de transmissão de um discurso, pois ele imprime certos aspectos em seu conteúdo, direcionando, inclusive, os usos que se pode fazer dele. Entretanto, ao considerarmos um gênero de discurso, não podemos apenas considerar o suporte material - oral, escrito, manuscrito, televisivo - e sim todo o circuito que organiza a fala. Na comunicação, o ponto de partida é sempre um gênero de discurso que integre logo de imediato com o mídium. "O modo de transporte e de recepção do enunciado condiciona a própria constituição do texto, modela o gênero de discurso" (MAINGUENEAU, 2005, p. 72).

Nessa perspectiva, defendemos que a embalagem é um suporte material do gênero anúncio, mas também um modo de difusão, já que se constitui em uma forma de comunicação com o sujeito consumidor do produto que carrega. Com o advento do sistema de autoatendimento, a figura do vendedor nos estabelecimentos comerciais desaparece, e a embalagem, junto com as campanhas publicitárias, é que desempenha a função de vender o produto, informando suas características ao consumidor. 
Mestriner (2007, p. 5) esclarece que

à medida que a propaganda, baseada na mídia e na veiculação de campanha de anúncios, vem perdendo espaço para outras ferramentas de marketing e para as ações 'na mídia', a embalagem assume uma nova dimensão no composto de marketing, pois pode servir também como veículo de comunicação, conduzindo mensagens publicitárias e diretas aos consumidores do produto.

$\mathrm{Na}$ criação desse suporte, estão implicados aspectos estéticos, técnicos e práticos. Os aspectos estéticos indicam as ideias que se desejam transmitir, disso decorre as cores, grafismo, molduras, tipos de letras, texto impresso; os aspectos técnicos são os que se relacionam com o material da embalagem, a utilidade, o descarte, aquilo que as autoridades determinam para embalar cada tipo de produto; os aspectos práticos têm relação com a facilidade de abrir, fechar, guardar entre outros. A embalagem, bem como a marca, é responsável pela identificação do produto; já os aspectos visuais também protegem a embalagem de imitação e facilitam "a transmissão do nível de qualidade agregado ao produto" (STREHLAU, 1996, p. 118).

Strehlau (1996, p. 52) assevera que, na embalagem, algumas características são fundamentais como os "fatores mentais subjetivos", fatores funcionais e a estrutura visual. Como "fatores mentais subjetivos", considera-se a embalagem uma forma de comunicação com o consumidor, pois ela apresenta a ele o produto. Considera-se também que o consumidor não compra apenas por uma satisfação física, mas emocional e social. Já os fatores funcionais consistem nas conveniências da embalagem para o consumidor e para o varejista. Strehlau (1996, p. 53) esclarece que "quando a 
embalagem não é conveniente ou eficiente, o consumidor pode vir a expressar alguma hostilidade com relação à marca”. A estrutura visual, por sua vez, refere-se à rapidez de percepção da embalagem entre as demais.

A utilização da embalagem como mídia vem se ampliando com soluções inovadoras e criativas, apresentando resultados satisfatórios de tal modo que é considerada uma ferramenta de marketing. As mensagens que conduz potencializam a propaganda, abrindo novas possibilidades sem aumentar o custo do produto. Todas as ações da campanha publicitária de um produto - seus anúncios, slogans, personagens entre outros - são reproduzidos na embalagem para ligar o produto a sua comunicação e aumentar o número de mensagens veiculadas.

No caso dos produtos para criança, em que os anúncios na mídia convencional são muito visados pelos órgãos de controle, a embalagem se torna ainda mais essencial para o produto, pois é ela que vai comunicar-se com os consumidores - crianças e seus responsáveis - nos pontos de venda.

Maingueneau (2015, p. 28) também esclarece que o discurso "só adquire sentido no interior de um imenso interdiscurso", ou seja, para compreendermos um enunciado, precisamos relacioná-lo a outros tipos de enunciados. Quando apreendemos um texto, realizado em determinado gênero de discurso, esse texto, de alguma forma, se prende a outros textos, nem sempre do mesmo gênero.

Maingueneau (2015, p. 122) expõe que "enunciar não é apenas ativar as normas de uma instituição de fala prévia; é construir sobre essa base uma encenação singular da enunciação: uma cenografia”. A noção de cenografia indica que um enunciador, por meio da enunciação, organiza o modo como quer enunciar. 
Maingueneau (2013, p. 98) afirma:

uma cenografia só se manifesta plenamente se puder controlar o próprio desenvolvimento, se puder manter uma distância em relação ao co-enunciador. Já num debate, por exemplo, é muito difícil que os participantes possam enunciar por intermédio de suas próprias cenografias: eles não têm o controle da enunciação e precisam reagir imediatamente a situações imprevisíveis suscitadas pelos interlocutores. Em situação de interação viva, o que frequentemente passa ao primeiro plano é, então a ameaça sobre as faces e o ethos.

A cenografia implica um processo de "enlaçamento paradoxal", pois ela é ao mesmo tempo aquela de onde vem o discurso e aquela que ele engendra; "ela legitima um enunciado que, por sua vez, deve legitimá-la, deve estabelecer que essa cena de onde a fala emerge é precisamente a cena requerida para enunciar" (MAINGUENEAU, 2008b, p. 77). O discurso publicitário, em se tratando da cenografia, tem condição diferenciada, pois não deixa antever a cenografia que será instaurada.

A concepção de ethos, por sua vez, proposta por Maingueneau (2013), não se relaciona, como na Retórica Antiga, às propriedades que os oradores conferem a si mesmos, mas à personalidade que constroem por meio de qualquer discurso oral ou escrito. A noção de ethos não se configura apenas em discurso persuasivo, cuja projeção da imagem é responsabilidade apenas do orador. Trata-se de um processo de adesão dos sujeitos a uma posição discursiva em que a projeção da imagem está estreitamente relacionada à cena enunciativa, na qual não se pode prescindir de outros elementos, tais como o co-enunciador, o lugar, o momento em que se discursa. 
Maingueneau (2013) defende que o texto possui um tom que dá autoridade ao que é dito. Tal tom propicia ao leitor construir uma representação do enunciador, ou seja, "a leitura faz emergir uma instância subjetiva que desempenha o papel de fiador do que é dito" (MAINGUENEAU, 2013, p. 107). O leitor constrói a figura do fiador por indícios textuais de diversas ordens e atribui a ele um caráter e uma corporalidade que varia de um texto para outro. O caráter é um conjunto de traços psicológicos e a corporalidade corresponde a uma maneira de ser. Maingueneau (2013, p. 108) explica que

o ethos implica, com efeito, uma disciplina do corpo apreendido por intermédio de um comportamento global. Caráter e corporalidade do fiador provêm de um conjunto difuso de representações sociais valorizadas ou desvalorizadas, sobre as quais se apoia a enunciação que, por sua vez, pode confirmá-las ou modificá-las. Esses estereótipos culturais circulam nos domínios mais diversos: literatura, fotos, cinema, publicidade etc.

Para o autor, não se pode considerar o ethos discursivo da mesma maneira em qualquer texto, pois a incorporação não é um processo uniforme; ela se ajusta com base nos gêneros e nos tipos de discurso. Por exemplo, o ethos, em um texto escrito, não necessariamente estabelece uma relação direta com um fiador socialmente determinado, ele pode não se referir a um estereótipo social delimitado, pode ser suscetível de atingir categorias sociais muito diferentes. Dessa forma, Maingueneau (2008a, p. 71) alerta para o fato de que a adesão do co-enunciador se dá por um apoio recíproco da cena de enunciação de que o ethos participa e do conteúdo apresentado 
a cenografia, como o ethos da qual participa, implica um processo de enlaçamento: desde sua emergência, a fala é carregada de certo ethos, que de fato se valida progressivamente por meio da própria enunciação. A cenografia é, assim, ao mesmo tempo, aquilo de onde vem o discurso e aquilo que esse discurso engendra: ela legitima um enunciado que, por sua vez, deve legitimá-la, deve estabelecer que essa cena da qual vem a palavra é precisamente a cena requerida para enunciar nessa circunstância.

Daí afirmarmos que, na Análise do Discurso, o ethos não pode ser visto como na Retórica, apenas como um modo de persuasão, pois ele é parte da cena da enunciação, com a mesma importância que tem o vocabulário ou os modos de propagação que o enunciado exige por seu modo de existência.

\section{Ethos discursivo nas embalagens de alimentos para crianças}

Analisamos o discurso da frente da embalagem para identificar que ethos discursivo é projetado na cenografia desse discurso. Analisamos também a lista de ingredientes dos produtos, que, geralmente, fica no verso ou na lateral das embalagens, a fim de verificar se o ethos discursivo projetado pelo enunciador no discurso da embalagem é incorporado pela descrição nutricional do alimento, tendo em vista a classificação dos alimentos proposta pelo Ministério da Saúde (2014). Na amostra selecionada, o enunciador é a marca do produto e o co-enunciador são os consumidores infantojuvenis e seus responsáveis. 


\section{Discurso 1. Bolinho sabor chocolate ${ }^{12}$}

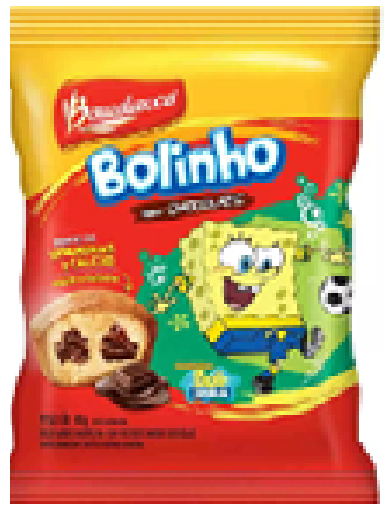

Bolinho sabor chocolate é um produto encontrado em supermercados, padarias, lanchonetes, mercearias e outros estabelecimentos do ramo alimentício. Ele é fabricado pela empresa Bauducco, bastante conhecida pela comercialização de bolos, biscoitos, panetones entre outros produtos. A embalagem é apresentada nas cores vermelha e amarela vibrantes com o logo da empresa na parte superior.

12 Lista de ingredientes: açúcar, farinha de trigo enriquecida com ferro e ácido fólico, ovo integral, gordura vegetal, açúcar invertido, glicose, clara de ovo, gotas sabor chocolate (açúcar, gordura vegetal, cacau em pó, soro de leite, permeado de soro de leite, emulsificante, lecitina de soja, estabilizante triestearato de sorbitana e aromatizante), amido modificado, óleo de milho, farinha de soja integral, carbonato de cálcio, cacau em pó, farinha de rosca, sal, líquor de cacau, vitaminas B1, B2, niacina, B6 e a fibra de aveia, umectantes: sorbitol e glicerina, emulsificantes: mono e diglicerídeos de ácidos graxos, lecitina de soja, monoestearato de glicerina e ésteres de ácido ricinoléico interesterificado com poliglicerol, conservadores: propinato de cálcio e sorbato de potássio, fermento em pó químico (amido, fermentos químicos: pirosfosfato ácido de sódio, bicarbonato de sódio e fosfato monocálcico, aromatizantes e acidulante: ácido cítrico e gelificante pectina. Fonte da imagem: <https://produto.mercadolivre.com.br/ MLB-1003294942-kit-20-bolinhos-bob-esponja-gotas-de-chocolate-bauducco-40g-_JM?quantity=1>. Acesso em: 12 jul. 2018. 
$\mathrm{Na}$ embalagem, a imagem reproduz o bolinho cortado ao meio para que se possam ver as gotas de chocolate, perto de um tablete de chocolate derretendo. Ao lado dessa imagem está o Bob Esponja, no fundo do mar, com uniforme da seleção brasileira "batendo uma bolinha", como se diz na gíria do futebol. A empresa detentora dos direitos autorais desse desenho é a Nicklodeon, referenciada na embalagem. Bob é uma esponja-do-mar quadrada que trabalha no Siri Cascudo e, nas horas vagas, diverte-se arrumando confusão com seu amigo estrela-do-mar Patrick. Trata-se de um desenho animado popular entre as crianças.

Além da imagem do produto e do Bob Esponja, há na embalagem os seguintes enunciados: "Bolinho sabor chocolate", "fonte de vitaminas e cálcio", "macio e fofinho", mais embaixo, há a descrição do produto: "Bolo sabor baunilha com recheio sabor chocolate", e a frase "Contém aromatizante sintético idêntico ao natural". Há ainda o peso do produto e a informação de que a foto é ilustrativa.

O enunciador se vale de outros discursos para compor a cenografia como o discurso do Ministério da Saúde que defende para a criança uma alimentação rica em vitaminas e cálcio por estarem em fase de crescimento. Essa informação aparece na embalagem em letras menores, pois é uma informação que interessa aos pais ou aos responsáveis e não às crianças. Há também o discurso das próprias crianças que elegem sempre o sabor chocolate como preferido, por isso o produto aparece cortado para que se visualizem as gotas de chocolate, reforçadas pela imagem grande de um tablete de chocolate que está ao lado.

A imagem do bolinho é grande, fácil de se visualizar, ainda que o nome remeta a algo pequeno "bolinho". O sufixo -inho, nesse caso, é um diminutivo, indica que a porção é pequena, ideal para uma criança, ou ainda, faz referência à forma como os adul- 
tos geralmente falam com as crianças. Ao se valer da imagem do personagem do desenho animado, o enunciador tem seu discurso ratificado por ele. O Bob Esponja, reproduzido na embalagem, é um sujeito que se identifica com os brasileiros, pois gosta de futebol, veste o uniforme da seleção brasileira, valoriza essa paixão nacional e, portanto, consome o bolinho de chocolate.

A imagem do produto projetada no discurso da embalagem é de um produto gostoso, já que tem chocolate, e saudável porque é uma fonte de vitaminas e cálcio muito importante para a criança em idade de crescimento. Trata-se de um produto indicado pelo Bob Esponja, um personagem conhecido das crianças. $\mathrm{O}$ fato de Bob Esponja estar com a bola de futebol e o uniforme da seleção brasileira contribui para uma identificação com o personagem e despertará a simpatia das crianças brasileiras que gostam de futebol. No Brasil, os jogos da seleção mobilizam a todos: adultos e crianças. Nessa cena, o produto, além de gostoso, desperta simpatia, alegria, ou seja, a alegria que os brasileiros sentem ao torcer pela seleção brasileira de futebol.

Dessa cenografia, emerge um ethos discursivo de um enunciador conectado com as preocupações de seu tempo que é, de um lado, a necessidade de se oferecer para a criança uma alimentação saudável "fonte de vitaminas e cálcio", e, de outro, um alimento que satisfaça o paladar da criança "Bolinho sabor chocolate", "macio e fofinho".

No entanto, segundo o Ministério da Saúde (2014), esse produto é considerado ultraprocessado, por isso deve ser evitado na alimentação das crianças, especialmente menores de dois anos. $\mathrm{Na}$ embalagem, a frase "Contém aromatizante sintético idêntico ao natural” dá a primeira pista de que esse alimento é ultraprocessado por conter um aditivo (aromatizante sintético) que imita o aroma de um alimento natural. 
$\mathrm{Na}$ lista de ingredientes, os ingredientes estão em ordem decrescente, isto é, os ingredientes listados primeiro são os que contêm em maior quantidade no produto. Nesse bolinho, os ingredientes do recheio sabor chocolate são: açúcar invertido, açúcar e gordura vegetal, seguidos de alguns outros ingredientes, como cacau em pó e fibra de aveia (e não aveia) e uma lista extensa de aditivos alimentares como emulsificante, lecitina de soja, estabilizante triestearato de sorbitana e aromatizante.

Nos ingredientes da massa, o açúcar é listado antes mesmo da farinha de trigo, o que significa que a massa contém mais açúcar do que a própria farinha, algo que não aconteceria se o bolo fosse preparado em casa a partir de alimentos in natura ou minimamente processados e ingredientes culinários. Também é adicionado ao produto vitaminas como B1, B2, B6 que, em alimentos ultraprocessados, é bastante comum, pois permite que se diga que o produto é rico em vitaminas, ainda que, como um todo, seja um alimento de baixa qualidade nutricional. Segundo as diretrizes do Ministério da Saúde, o açúcar deve ser evitado por, pelo menos, os dois primeiros anos de vida. A gordura vegetal, nesse caso, muito provavelmente é gordura trans, que também deve ser evitada por estar associada às doenças do coração.

Dessa forma, a imagem de si nesse discurso se desfalece, se descorporifica quando analisada a lista de ingredientes, já que se trata de um alimento ultraprocessado. 


\section{Discurso 2. Bisnaguinha Scooby-Doo! Integral ${ }^{13}$}

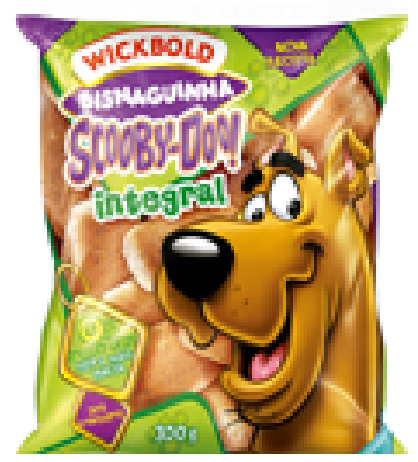

Bisnaguinha Scooby-Doo! Integral é um pãozinho fabricado pela empresa de gênero alimentício Wickbold, cujo logo fica no alto da embalagem. É um produto encontrado nos supermercados de modo geral e em outros comércios do mesmo gênero. A parte central da embalagem é transparente, o que possibilita visualizar o produto. Nas laterais, a embalagem é verde e roxa, cores vibrantes.

Na embalagem, há a imagem do Scooby-Doo na cor marrom. Scooby-Doo é um desenho animado americano, foi produzido pela Hanna-Barbera, em 1969. Trata-se de um desenho com o maior número de temporadas, por isso é muito conhecido não só das crianças, mas também de seus pais. Scooby-Doo é um dogue alemão falante que acompanha quatro pessoas que se propõem a investigar casos misteriosos ${ }^{14}$.

13 Lista de ingredientes: Farinha de trigo integral, farinha de trigo enriquecida como ferro e ácido fólico, frutose, açúcar, glúten, óleo de soja, fibra de trigo, açúcar mascavo, sal, sal hipossódico e conservador propionato de cálcio. Fonte da imagem: <https://www.wickbold.com.br/linhas-produtos/linha-bisnaga//\#bisnaguinha-Scooby-Doo-integral>. Acesso em 12 jul. 2019.

14 Disponível em: <https://pt.wikipedia.org/wiki/Scooby-Doo.> Acesso em: 10 mai. 2019. 
$\mathrm{Na}$ embalagem, há a informação, em letras menores, de que se trata de uma "nova receita", e na medalhinha dourada do Scooby-Doo mais à esquerda, há os dizeres "zero gordura trans", "agora mais macia", e abaixo "sem colesterol".

Nessa embalagem, os enunciados "nova receita", com "zero gordura trans", "agora mais macia", "sem colesterol” são informações dadas aos co-enunciadores adultos para dar a impressão de que se trata de um produto saudável. Nesses enunciados, identifica-se o discurso do Ministério da Saúde (2014), que alerta para os riscos de uma alimentação com excesso de gordura trans e colesterol e recomenda que os alimentos consumidos sejam preferencialmente integrais. A palavra receita na embalagem remete ao fazer culinário caseiro, prática também recomendada pelo Guia, e não ao industrializado.

Nessa cenografia, o ethos discursivo do enunciador que emerge é de uma empresa que oferece um alimento gostoso, ainda que integral, pois muitos, especialmente as crianças, não apreciam o sabor de alimentos feitos com farinha integral pela textura que têm. Trata-se de um produto saudável, não possui gordura trans, nem colesterol. Assim, espera-se que o produto seja visto como um alimento ideal para as crianças, uma solução prática e saudável para o lanche escolar, por exemplo.

A presença do Scooby-Doo na embalagem agrega ao produto a simpatia dessa personagem de desenho animado, conhecida pelos consumidores pais e crianças, já que o desenho atravessa gerações. O uso do diminutivo no nome do produto (bisnaguinha) e o fato de ser um pãozinho pequeno, também dá indícios de que esse é um alimento ideal para crianças, pois o tamanho da bisnaguinha é compatível com a quantidade que uma criança geralmente consome. 
No entanto, quando se observa a lista de ingredientes, é possível constatar que contém dois tipos de açúcar listados: açúcar e frutose. O segundo é um outro tipo de açúcar bastante usado pela indústria alimentícia e que não é usado quando se faz um pão caseiro, por exemplo. Além disso, contém listado sal duas vezes: sal e sal hipossódico, usado como substituto ou complemento do sal regular para evitar que o alimento tenha uma quantidade de sódio muito elevada, um micronutriente bastante conhecido da população por ser associado a doenças como a hipertensão se consumido em excesso. Há também um aditivo alimentar, o proprionato de cálcio, um conservador. O produto não contém só farinha integral, há a integral e a farinha branca enriquecida de ferro e ácido fólico.

Embora o ethos discursivo desse enunciador é de empresa preocupada em comercializar um produto saudável, com propriedades importantes para uma criança que está em crescimento como o ferro, a lista de ingredientes descontrói essa imagem por se tratar de um alimento ultraprocessado. 


\section{Discurso 3. Toddynho Levinho ${ }^{15}$}

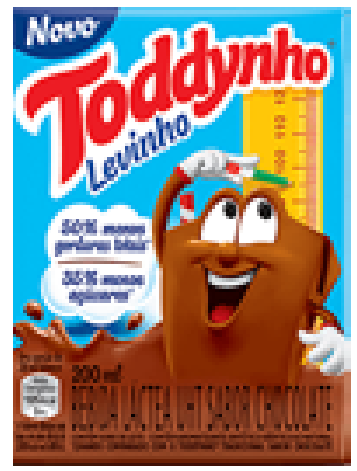

A bebida láctea achocolatada Toddynho Levinho é um produto da empresa do grupo Pepsico, "empresa transnacional, estadunidense, de alimentos, lanches e bebidas com sede em Purchase, Nova Iorque"16. O Toddynho é fabricado e distribuído no Brasil, encontrado em supermercados, cantinas escolares e outras empresas do gênero alimentício, principalmente aquelas que procuram atender o público infantojuvenil.

Não há nessa embalagem um personagem de desenho animado como nas anteriores, mas há o personagem Toddynho, representação do próprio alimento com uma carinha simpática, braços e mãos. No canto superior da embalagem, lê-se "Novo Toddynho

15 Lista de ingredientes: Soro de leite reconstituído, leite integral reconstituído, calda de cacau (água e cacau), leite desnatado reconstituído, açúcar, estrato de malte cevada, fosfato tricálcico, vitaminas (maltodextrina, ácido L - ascóbico (vitamina C), acetato de retinila (vitamina A) e ácido fólico (vitamina B9), Vitamina D3, espessantes: carboximetilcelulose sódica, goma xantana, goma gelana e carragena, aromatizantes, estabilizantes; fosfato dipotássico e citrato de sódio e emulsificantes lecitina de soja. Fonte da imagem: <https://www.Toddynho.com. br/>. Acesso em: 12 jul. 2019.

16 Disponível em: <https://pt.wikipedia.org/wiki/PepsiCo>. Acesso em: 21 mai. 2019. 
Levinho”. Mais abaixo, em uma nuvem, há os dizeres: “50\% menos gorduras totais" e "35\% menos açúcares". No final das duas frases, há um asterisco em que a explicação se encontra em letras menores na parte inferior da embalagem: "quando comparado com o Toddynho tradicional sabor chocolate". Na frente da embalagem também se encontra a descrição do produto "Bebida láctea UHT sabor chocolate" e as frases "Contém soro de leite - Contém aromatizante sintético idêntico ao natural”. Além disso, é apresentado que a porção de $200 \mathrm{ml}$ contém valor energético de $105 \mathrm{kcal}$, ou seja, 5\% dos valores diários com base uma dieta de $2000 \mathrm{kcal}$ ou $8400 \mathrm{~kJ}$. Na embalagem, Toddynho está na frente de uma régua, marcando a sua altura com um lápis. A letra da palavra Toddynho, no topo superior da embalagem, é vermelha e a régua amarela, contrastando com o fundo azul claro do restante da embalagem e da nuvem branca.

O enunciador desse discurso é o Toddynho, pois a empresa Pepsico não aparece no discurso da frente da embalagem, há um apagamento da empresa para que o produto seja o enunciador, o que reforça a imagem do produto. $\mathrm{O}$ enunciador informa na embalagem que se trata de um novo Toddynho, com uma nova fórmula que contém menos açúcar e menos gordura. Pode-se inferir que a presença da régua, além de marcar o crescimento da mascote, remete os pais ao material escolar, lembrando-os da necessidade de opções práticas para a lancheira. Nesse caso, o Toddynho é perfeito, pois já está embalado e a criança toma com o canudo que acompanha o produto, além de não precisar ser refrigerado.

Na representação do personagem Toddynho diante da régua, o enunciador leva o co-enunciador a inferir que quem toma a bebida láctea cresce, se desenvolve como o Toddynho tem se desenvolvido. Nesse caso, o enunciador reforça o discurso do Ministério da Saúde que recomenda o consumo de leite às crianças por ser uma fon- 
te de cálcio e proteínas, nutrientes importantes para as crianças em fase de crescimento. Há ainda o discurso das crianças que dizem querer crescer até o céu. $O$ fundo azul e as nuvens na embalagem sugerem que o Toddynho cresceu tanto que está da mesma altura do céu, por isso está feliz, sorrindo.

$\mathrm{Na}$ cenografia construída por esse interdiscurso, emerge o ethos discursivo do Toddynho. Trata-se de um produto "leve", mais saudável que o Toddynho tradicional, porque tem menos gordura e menos açúcar. Ele contribuiu, de modo saudável, para o desenvolvimento das crianças e as crianças que crescem são felizes, alegres. $\mathrm{O}$ enunciador também se preocupou com os pais, criando uma opção de lanche para as crianças.

Entretanto, não é porque a fórmula nova tem menos açúcar e menos gordura, que necessariamente é saudável. Nesse caso, esse produto continua sendo classificado como um alimento ultraprocessado, pois, na sua extensa lista de ingredientes, encontram-se diferentes formas de açúcar e muitos outros ingredientes não convencionais que jamais se usaria se estivesse preparando uma versão caseira desse alimento. Alguns exemplos são: soro de leite reconstituído, extrato de malte de cevada, espessantes, aromatizantes.

Ao informar na embalagem que se trata de valor energético de $105 \mathrm{kcal}, 5 \%$ dos valores diários com base em uma dieta de 2000 kcal ou $8400 \mathrm{~kJ}$, vale ressaltar que a dieta de 2000 calorias é uma referência para um adulto e não para uma criança. A ingestão calórica de uma criança, dependendo da idade, é bem menor que 2000 calorias.

O ethos discursivo do alimento Toddynho, projetado no anúncio publicitário da embalagem, desfalece na análise nutricional, com base no que defende o Ministério da Saúde, por se tratar de um alimento ultraprocessado. 


\section{Discurso 4. Fandangos ${ }^{17}$}

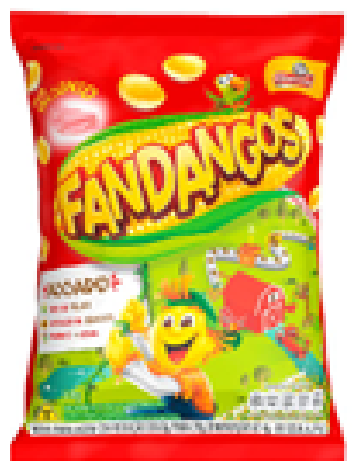

O salgadinho Fandangos é produzido pela Elma Chips, empresa brasileira do ramo de alimentação, administrada pela Frito-Lay, do grupo americano Pepsico, assim como o Toddynho. A Elma Chips tem "uma linha variada de produtos para diferentes consumidores. A marca se tornou muito conhecida por seu slogan: 'É impossível comer um só' "18. Os salgadinhos são vendidos em supermercados, em cantinas escolares, em bares, em padarias, em bancas de jornal, entre outros estabelecimentos.

Predominam na embalagem do Fandangos as cores vermelha e amarela vibrantes que destacam a embalagem. Vermelho é a cor do logo da marca que fica do lado direito, no alto da embalagem e o amarelo é a cor do produto. $\mathrm{Na}$ embalagem, há a representação de uma espiga de milho, de um papagaio e da mascote do produto, 17 Lista de ingredientes: Farinha de milho fortificada com ferro e ácido fólico, óleos vegetais de girassol, palma e soja, preparado para salgadinho sabor presunto (sal, cloreto de potássio, farinha de arroz, aromatizantes, realçadores de sabor: glutamato, monossódico, inosinato dissódico e guanilato dissódico, antiumectante dióxido de silício, acidulante ácido cítrico e urucum) e sal. Fonte da imagem: <https://www.tendadrive.com.br/salgad-elma-chips-Fandangos-pres-59g-9253/p>. Acesso em: 12 jul. 2019.

18 Disponível em: <https://pt.wikipedia.org/wiki/Elma_Chips>. Acesso em: 21 mai. 2019. 
a Spiggy. Trata-se de um espantalho que vive em uma fazenda e infere-se que esteja auxiliando na plantação do milho que servirá para preparar os salgadinhos.

O nome Spiggy remete ao substantivo espiga, para reforçar a ideia de que o produto é feito de milho. Observa-se na embalagem, ao fundo do Spiggy, uma fazenda onde supostamente o salgadinho é produzido. $\mathrm{Na}$ entrada de uma construção, tem um caminhão chegando cheio de espigas de milho e do outro lado, sai uma esteira com os pacotes de salgadinho.

A embalagem contém uma imagem de fatias de presunto e informa que o sabor do salgadinho é presunto, que ele é assado, feito de milho e que contém óleo de girassol. Também alerta para o fato de que "dividir é + legal". A empresa também informa que se trata de uma "Nova embalagem com redução de $175 \mathrm{~g}$ para $164 \mathrm{~g}$ (diminuição de $11 \mathrm{~g}$, ou seja, 6,3\%)". No canto esquerdo inferior, observamos a presença de um símbolo triangular amarelo com um T em preto, que indica que o produto contém ingredientes transgênicos.

Nesse discurso, o co-enunciador, ainda que a marca vise a diferentes consumidores, é o consumidor criança que se infere pela representação da fazendinha, do espantalho Spiggy e do papagaio os quais remetem ao universo infantil. Há aí o discurso de que produtos assados são mais saudáveis do que os fritos, por isso essa informação consta da embalagem, ela é importante para o consumidor. $\mathrm{O}$ enunciador também defende o consumo do óleo de girassol, em vez de outros óleos e gorduras, como a trans. Como o produto contém muita gordura, o enunciador avisa que é óleo de girassol, ou seja, é como se dissesse: tem muito óleo, mas é óleo saudável. Há também, nesse discurso, a forte referência à comida de fazenda, conhecida por ser tradicional, gostosa, caseira e saudável. O produto é ainda associado à espiga de milho, um alimento 
natural, recomendado no Guia alimentar para a população brasileira (2014). Vale ainda ressaltar a recomendação feita no Guia sobre o momento da refeição, que deve ser um momento de compartilhamento. Assim a criança não comerá sozinha o pacote todo, e, dessa forma, terá oportunidade de socializar com outras crianças.

Ao observar a lista de ingredientes do produto Fandangos, é possível notar que o primeiro ingrediente é farinha de milho, seguido de óleos vegetais de girassol, palma e soja e não somente de girassol, como é enfatizado na frente da embalagem. Além disso, o produto contém um preparado de sabor presunto e não presunto de verdade. Esse preparado é feito com sal, cloreto de potássio, farinha de arroz e aditivos que não são adequados para as crianças. Além disso, o produto é feito de ingredientes transgênicos, ou seja, geneticamente modificados. Alimentos transgênicos são produzidos em larga escala, com uso extensivo de agrotóxicos e outros recursos naturais que têm um grande impacto no meio ambiente. No Guia alimentar, defende-se que uma alimentação saudável deve derivar-se de um sistema alimentar ambientalmente sustentável e justo, o que frequentemente não ocorre na produção de alimentos ultraprocessados.

O ethos discursivo desse enunciador se volta para o de uma empresa que fabrica um produto saudável, porque é de milho colhido na fazenda; defende que as refeições sejam um momento de compartilhamento, o que é muito saudável para as crianças por ser um momento de união familiar. Todavia, esse ethos discursivo se desfaz quando confrontado com a lista de ingredientes, a qual caracteriza o alimento como ultraprocessado. 


\section{Discurso 5. Danoninho ${ }^{19}$}

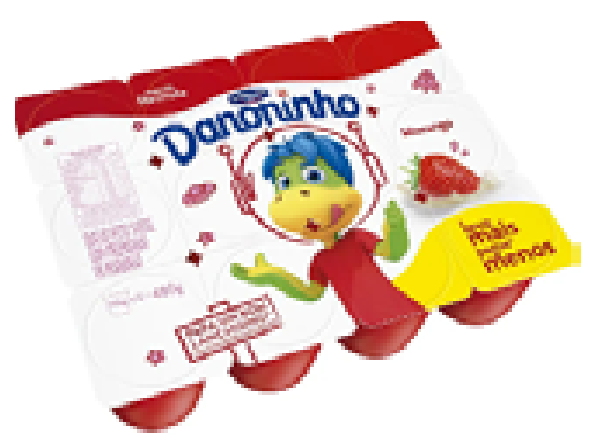

A última embalagem analisada é do Danoninho, fabricado pela Danone, empresa multinacional com sede em Paris, na França. O Danoninho é encontrado em supermercados, padarias, mercearias, entre outros estabelecimentos de produtos alimentícios.

Na embalagem do Danoninho, com o nome da marca Danone na parte superior, a figura que sobressai é a da mascote do produto, o dinossauro Dino com um fone de astronauta. A nave aparece mais ao fundo. Também aparece em destaque a imagem e o nome da fruta - morango - com a qual o petit suisse é supostamente preparado. É informado ainda que se trata de uma nova fórmula e que o produto serve "para um bom lanchinho: uma opção para compor um lanchinho dentro de uma dieta balanceada”. Do lado esquerdo da embalagem, estão as informações nutricionais do produto, o seu peso e a informação de que se trata de "queijo petit

19 Lista de ingredientes: leite desnatado, xarope de açúcar, preparado de fruta (água, frutose, polpa de morango, fosfato tricálcico, amido modificado, gluconato de zinco, vitamina E, maltodextrina, bisglicinato ferroso, vitamina D, acidulante ácido cítrico, corante natural carmim cochonilha, aromatizante, espessantes goma carragena, carboximetilcelulose e goma xantana e conservador sorbato de potássio), creme, frutose, cloreto de cálcio, fermento lácteo, quimosina e espessantes carboximetilcelulose e goma guar. Fonte da imagem: $<$ https:// www.Danoninho.com.br>. Acesso em 12 jul. 2019. 
suisse com preparado de frutas". A embalagem é vermelha vibrante da cor do morango e o papel que a cobre é branco, o que remete ao leite com o qual o queijo é preparado.

O produto Danoninho ficou conhecido com o slogan "vale por um bifinho", muito criticado por nutricionistas e outros profissionais da saúde, que alegavam ser uma propaganda enganosa. Hoje, é anunciado como sendo um complemento da alimentação infantil, em razão de ter na sua composição leite da vaca. Segundo a página do produto, "diferentemente do iogurte, na fabricação do petit suisse, inclui-se a etapa de concentração da massa, com a retirada do soro do leite, o que resulta em uma consistência mais densa e um teor maior de proteína e cálcio" ${ }^{20}$.

Nesse discurso, o enunciador informa que se trata de uma nova fórmula, o que leva o co-enunciador a considerar o produto melhor do que o produzido anteriormente. A representação da fruta confirma o que está enunciado em "petit suisse com preparado de morango". Já a mascote remete o co-enunciador ao universo infantil, pois as crianças apreciam muito os dinossauros, os astronautas, as naves espaciais. Além da mascote, o nome do produto também remete a esse universo por estar no diminutivo - Danoninho.

$\mathrm{Na}$ cenografia construída por esse discurso, o ethos discursivo do enunciador é de empresa que produz um alimento saudável para as crianças de modo geral, pois ela recomenda o produto como uma opção de lanche, ou seja, um alimento para ser oferecido no intervalo das refeições. Além de saudável, a empresa se preocupou com sabor, pois morango é um sabor que agrada o paladar das crianças.

20 Disponível em: <https://pt.wikipedia.org/wiki/Danoninho\#Hist\%C3\%B3ria>. Acesso em: 22 mai. 2019. 
O Danoninho, assim como outros produtos, se vale da estratégia de se vincular a um grupo de alimento saudável, que são as frutas. No entanto, na sua extensa lista de ingredientes não se encontra fruta de verdade, mas sim um preparado de fruta feito de água e frutose em quantidade maior do que a polpa de morango. Além do açúcar, esse produto contém aditivos alimentares como fosfato tricálcico, amido modificado, gluconato de zinco. Em razão de conter tais aditivos, o SAC ${ }^{21}$ (Serviço de atendimento ao consumidor) da empresa informa aos consumidores, que fazem contato, que esse alimento não é adequado para crianças menores de três anos de idade, porém essa informação não consta da embalagem do produto.

Dessa forma, o ethos discursivo de um enunciador, preocupado em oferecer um alimento saudável, preparado com a fruta, projetado na cenografia construída no discurso da embalagem, não é incorporado pela análise nutricional, pois o alimento é, na caracterização do Ministério da Saúde, um alimento ultraprocessado.

\section{Considerações finais}

Neste capítulo, examinamos o discurso das embalagens de produtos que têm como alvo os consumidores infantojuvenis. Identificamos o ethos discursivo do enunciador que emerge da cenografia construída na embalagem e verificamos se tal ethos discursivo é validado na análise nutricional do alimento, com base no Guia alimentar para a população brasileira, do Ministério da Saúde.

Em todos os discursos analisados, o ethos discursivo que se projeta dos enunciadores é de empresas comprometidas com a produção de alimento saudável, adequado para o consumo das 21 Ligação para o SAC da empresa 08007017561, no dia 01/08/2019, às 11 h56. 
crianças, pois incorporam as recomendações nutricionais consideradas saudáveis no Guia alimentar como o consumo de frutas, ricas em vitaminas; o consumo do leite, rico em cálcio; de alimentos naturais, como o milho; a refeição em família para que seja um momento de compartilhamento. No entanto, ao se verificar a lista de ingredientes, tal ethos discursivo se desfaz, pois os alimentos são ultraprocessados. Vale ressaltar que nas embalagens predominam as cores vibrantes como vermelho, amarelo, azul, verde que chamam a atenção. Os personagens estão sempre em destaque na embalagem, sendo os primeiros a serem visualizados, já que a criança não escolhe o produto pelas suas qualidades, isso é feito pelos seus responsáveis, mas pelo personagem que está na embalagem. Todas as embalagens analisadas apresentam as qualidades do produto também em destaque para que os pais ou responsáveis possam ter acesso a elas com facilidade. Afinal, como vimos, a embalagem é um mídium, pois é suporte para o produto e uma forma de difusão desse produto nos pontos de venda.

Vale observar ainda que, com exceção do salgadinho Fandangos, os demais têm nomes no diminutivo - Bolinho, Toddynho, Bisnaguinha, Danoninho - que remete ao universo infantil e estabelece uma aproximação com os pais, pois trata-se do jeito afetivo com que falam com seus filhos, ou como os adultos falam com as crianças.

\section{Referências}

BRASIL. Código de defesa do Consumidor. Disponível em: <http://www.planalto.gov.br/ccivil_03/leis/18078.htm>. Acesso em: 11 jun. 2019.

BRASIL. Estatuto da criança e do adolescente. Disponível 
em: <http://www.planalto.gov.br/ccivil_03/leis/18069.htm>. Acesso em: 11 jun. 2019.

BRASIL. Código Brasileiro de Autorregulamentação Publicitária. Disponível em: <http://www.conar.org.br/>. Acesso em: 11 jun. 2019.

BRASIL. Ministério da Saúde. Secretaria de atenção à saúde. Departamento de atenção Básica. Guia alimentar para a população brasileira. Brasília-DF, 2014.

DEBRAY, R. Manifestos Midiológicos. Petrópolis/RJ: Vozes, 1995.

Danoninho. Danoninho morango 320g. Disponível em: $<$ https://www.Danoninho.com.br>. Acesso em: 12 jul. 2019. DOCUMENTÁRIO. Muito além do peso. Produção: Maria Farinha Filmes. São Paulo, 2012.

ELMA CHIPS. Wikipédia, 2019. Disponível em https:// pt.wikipedia.org/wiki/Elma_Chips. Acesso em: 21 mai. 2019. MAINGUENEAU, D. Análise de textos de comunicação. 1. ed. São Paulo: Cortez, 2005.

. Cenas da enunciação. São Paulo: Parábola Editorial, 2008a.

. Ethos, cenografia, incorporação. In: AMOSSY, R. (Org.). Imagens de si no discurso: a construção do ethos. São Paulo: Contexto, 2008b.

. Discurso e Análise de Discurso. São Paulo: Parábola, 2015.

. Análise de textos de comunicação. 6. ed. São Paulo: Cortez, 2013.

MESTRINER, F. Gestão estratégica de embalagem. São Paulo: Pearson Prentice Hall, 2007.

NARDOCCI, I. M.; PAGOTTO, S. Z. "Gênero de discurso: anúncio publicitário de alimentos ultraprocessados". In: NASCIMENTO, J. V.; FERREIRA, A. (Orgs.) Discurso e Cultura. São Paulo: Blucher, 2018.

SCOOBY-DOO. Wikipédia, 2019. Disponível em: <https:// 
pt.wikipedia.org/wiki/PepsiCo>. Acesso em: 21 mai. 2019. SEABRA, Geraldo A. Poder de propaganda da embalagem de produtos não anunciados. Disponível em: <https://webinsider.com.br/o-poder-de-propaganda-da-embalagem-de-produtos-nao-anunciados-i/>. Acesso em 02 mai. 2019. STREHLAU, V. I. A embalagem e sua influência na imagem do produto. Dissertação (Mestrado em Administração). Fundação Getúlio Vargas. São Paulo, 1996.

PEPSICO, INC. Wikipédia, 2019. Disponível em: <https:// pt.wikipedia.org/wiki/PepsiCo>. Acesso em: 21 mai. 2019. 